\title{
IMPLEMENTAÇÃO DO PROGRAMA ENSINO MÉDIO INOVADOR MEDIADO PELAS METODOLOGIAS ATIVAS
}

\section{RELATO DE EXPERIÊNCIA}

XAVIER, Manoel Viana ${ }^{1}$

XAVIER, Manoel Viana. Implementação do programa Ensino Médio Inovador mediado pelas metodologias ativas. Revista Científica Multidisciplinar Núcleo do Conhecimento. Ano 05, Ed. 10, Vol. 10, pp. 121-130. Outubro de 2020. ISSN: 24480959, Link de acesso: https://www.nucleodoconhecimento.com.br/educacao/ensinomedio-inovador

\section{RESUMO}

Objetivo: Descrever a experiência vivenciada na implementação do Programa Ensino Médio Inovador, utilizando-se de Metodologias Ativas, por gestores, pedagogos, professores e auxiliares administrativos da Escola Estadual Nossa Senhora do Perpétuo Socorro, do município de Coari-AM, Brasil. Método: Estudo do tipo relato de experiência, realizado de fevereiro a dezembro de 2015. Na elaboração e concretização das práticas pedagógicas, a gestão escolar, os professores, alunos e demais auxiliares recorreram ao uso dos ambientes da escola, adequando-os às necessidades de cada atividade desenvolvida, buscando respostas às indagações do porquê e de como as atividades que utilizam as metodologias ativas proporcionam aos estudantes maior autonomia na construção das próprias aprendizagens e contribuem para que compreendam melhor os conteúdos e potencializem competências fundamentais, auxiliando na melhoria dos rendimentos escolares. No decorrer das práticas, foi necessário realizar diversas adequações na estrutura física da escola, que vieram proporcionar aos alunos ambientes favoráveis para execução das atividades desenvolvidas, como também implantar nova estrutura organizacional,

\footnotetext{
${ }^{1}$ Mestrando em Educação pela Universidad Autónoma de Asunción (UAA), AsunciónParaguai.
} 
sob forma de gerência, que introduziu novos projetos e reestruturou a implementação dos projetos existentes na escola. Resultados Alcançados: No decorrer do processo de captação da realidade, percebeu-se que, com as adequações na estrutura física na escola, implantação de nova estrutura organizacional, estabelecimento e implementação de novos projetos, foi possível criar ambiente favorável para prática das metodologias ativas e, consequentemente, proporcionar melhorias significativas no ensino e na aprendizagem dos educandos. Quanto ao resultado nos índices de aprendizagem, de acordo com o Sistema Integrado de Gestão Educacional do Amazonas, em 2014, a escola apresentou índice de aprovação dos alunos de 77,40\%, abaixo da média das outras escolas do município que foi 82,06\%. Em 2015, após intervenções, a escola atingiu índice de 92,84\%, superando a média das outras que foi de $79,91 \%$. Considerações finais: Os desafios enfrentados para implementação das práticas inovadoras serviram para fomentar a cultura de grupo e proporcionar trabalho interdisciplinar envolvendo toda a comunidade escolar, que possibilitou aos alunos da escola superarem os índices de aprendizagem do ano anterior.

Palavras-chave: Implementação, Ensino Médio Inovador, metodologias ativas.

\section{INTRODUÇÃO}

O art. 35 da Lei de Diretrizes e Bases da Educação Nacional (LDB) apresenta o Ensino Médio (EM) como a qualificação essencial que possibilitará ao jovem brasileiro adquirir habilidades e competências para desenvolver de maneira satisfatória o ofício por este escolhido, obtendo, assim, o meio de sobrevivência de forma justa e honesta, possibilita, ainda, aos educandos, condições para continuarem aprendendo, de modo a ser capaz de se adaptar com flexibilidade às novas condições de ocupação ou aperfeiçoamento posteriores (BRASIL, 1996).

O EM, no Brasil, ainda funciona em desacordo e conflitando com o conceito da Educação Básica e das necessidades de aprendizado dos alunos. Ao considerar a Lei de Diretrizes e Bases da Educação Nacional (LDBEN) de 1996, o EM não estaria atendendo ao conjunto de prioridades, concepções, propósitos, objetivos, diretrizes 
ou mesmo características que são destacados para essa etapa da educação no Brasil (VITELLI, 2017).

Em virtude do EM não ter correspondido às necessidades e expectativas dos jovens, principalmente, no que refere à inserção na vida profissional, como também não contribuiu com o crescimento social e econômico do país, fizeram-se necessárias mudanças e reformulação nessa modalidade de ensino.

Ao tentar superar essas dificuldades, o Ministério da Educação e Cultura (MEC) institui, por meio da Portaria nº. 971/2009, o Programa Ensino Médio Inovador (PROEMI), como ação educacional específica para escolas de EM, no intuito de garantir: universalização, permanência e aprendizagem significativa para maioria dos estudantes que cursam essa modalidade de ensino (BRASIL, 2009).

O PROEMI foi criado para atender à necessidade de instituir políticas educacionais para adolescentes e jovens, ofertando ensino de qualidade, fomentar propostas curriculares inovadoras nas escolas de EM e, como consequência, provocar o debate da modalidade junto aos sistemas educacionais (BRASIL, 2009).

Em 2009, o estado do Amazonas, com objetivo de alavancar os índices educacionais no EM, iniciou a participação no PROEMI, indicando dez escolas, sendo duas da capital e oito das demais cidades do estado. Das escolas selecionadas, sete de municípios do interior foram aprovadas pelo MEC para oferecer o Programa, dentre as contempladas, encontrava-se a Escola Estadual Nossa Senhora do Perpétuo Socorro, em Coari (ANDRADE, 2015).

Nesse contexto, enfatiza-se que a escola mencionada está localizada em Coari, município do interior do Amazonas, Região Norte do Brasil, distante $362 \mathrm{~km}$ de Manaus, capital do estado. Escola tradicional, fundada pelos Padres Redentoristas e pelas Irmãs Adoradoras do Preciosíssimo Sangue de Cristo, jurisdicionada à Coordenadoria Regional da Secretaria de Estado de Educação e Qualidade de Ensino do Amazonas (SEDUC-AM), no município de Coari. No ano de 2015, atendeu às modalidades: Ensino Médio Inovador, Ensino Médio Mediado por Tecnologia e 
Educação de Jovens e Adultos Mediado por Tecnologia, nos turnos: matutino, vespertino e noturno (SEDUC-AM, 2016).

Até fevereiro de 2015, as metodologias inovadoras apresentadas pelo PROEMI ainda não haviam acontecido na citada escola, devido à implantação não ter considerado o espaço físico, a capacitação adequada dos professores, a clareza dos objetivos e as finalidades do Programa aos incluídos no processo.

Segundo Silva (2017), a fase da implementação é o momento no qual a política pública é posta em prática e, nessa fase, é fundamental que se prepare eficazmente os implementadores, visto que estes não são os responsáveis pelo desenho da política. É mister que os envolvidos tenham clareza dos propósitos do programa, para que o mesmo aconteça de forma correta e atinja os objetivos almejados.

Xavier (2016 apud SILVA, 2017) descreve as dificuldades encontradas para aplicação do PROEMI na Escola Estadual Nossa Senhora do Perpétuo Socorro, tais como precariedade da estrutura física da escola, ausência de espaços físicos adequados para implementar oficinas e oferecer aula de reforço em contraturno, incessante rotatividade de docentes, interrompendo a sequência de determinada prática inovadora, carência de espaço físico apropriado para acomodar materiais dos laboratórios de Física, Matemática e Biologia.

Para que a implementação do PROEMI viesse acontecer, utilizando-se de métodos diferenciados e técnicas inovadoras, como as metodologias ativas, foi necessário proceder a mudanças na estrutura organizacional, adequações curriculares e incentivo à participação da família na escola.

A partir da década de 1980, ergueram-se as metodologias ativas, método didático oposto às práticas tradicionais, cuja apresentação oral dos conteúdos aos alunos, por parte do professor, caracteriza-se como a única ferramenta de transmissão das temáticas ensinada em sala de aula. Essas metodologias procuram criar ambiente de aprendizagem em que $o$ aluno é incentivado a apropriar-se de postura ativa no processo de aprender (MOTA; ROSA, 2018). 
Por dispor de ampla variedade de recursos didáticos, a metodologia ativa permite a utilização da sala de aula invertida, que propõe a inversão completa do modelo de ensino, a partir dos quatro pilares: ambiente de aprendizagem flexível, cultura de aprendizagem com enfoque no aluno, conteúdo dirigido pelo educador e presença de professor com postura profissional exigente e continuamente solicitada (BERGMANN; SAMS, 2016).

A sala de aula invertida é uma estratégia de aprendizagem com objetivo de melhorar o envolvimento e os resultados de alunos. Com a tecnologia da informação e comunicação presente na vida dos indivíduos, é comum encontrar alunos que utilizam de dispositivos eletrônicos, logo a escola não pode ficar afastada dessa realidade (RODRIGUES et al., 2019).

Observa-se que, nos dias atuais, ainda persiste resistência ou desconhecimento por parte dos envolvidos no processo de ensino e aprendizagem, no que tange à aceitação de modelo educacional fundamentado nas metodologias ativas de aprendizagem.

O presente estudo objetivou descrever a experiência vivenciada na implementação do PROEMI, utilizando-se das metodologias ativas por gestores, pedagogos, professores e auxiliares administrativos, da Escola Estadual Nossa Senhora do Perpétuo Socorro, do município de Coari - AM.

\section{DESENVOLVIMENTO}

Trata-se de estudo retratado, do tipo relato de experiência, sobre a implementação do PROEMI, mediado pelas metodologias ativas, por gestores, pedagogos, professores e auxiliares administrativos, da Escola Estadual Nossa Senhora do Perpétuo Socorro, do município de Coari - AM, Brasil. A prática foi realizada de fevereiro a dezembro de 2015 na referida escola.

Para realização da prática, uma nova estrutura organizacional foi implantada pela gestão da escola, com a participação de Conselho Escolar, professores e 
comunidade. Com base em estruturas funcionais, sob forma de gerência, cujos gerentes, encarregados de deliberações em áreas específicas, participaram das reuniões e tomadas de decisões do Conselho Escolar, no qual as resoluções gerais eram tomadas por consenso, formando estrutura administrativa participativa, conforme Figura 1.

Figura 1 - Descrição da estrutura organizacional, sob forma de gerência, da Escola Estadual Nossa Senhora do Perpétuo Socorro.

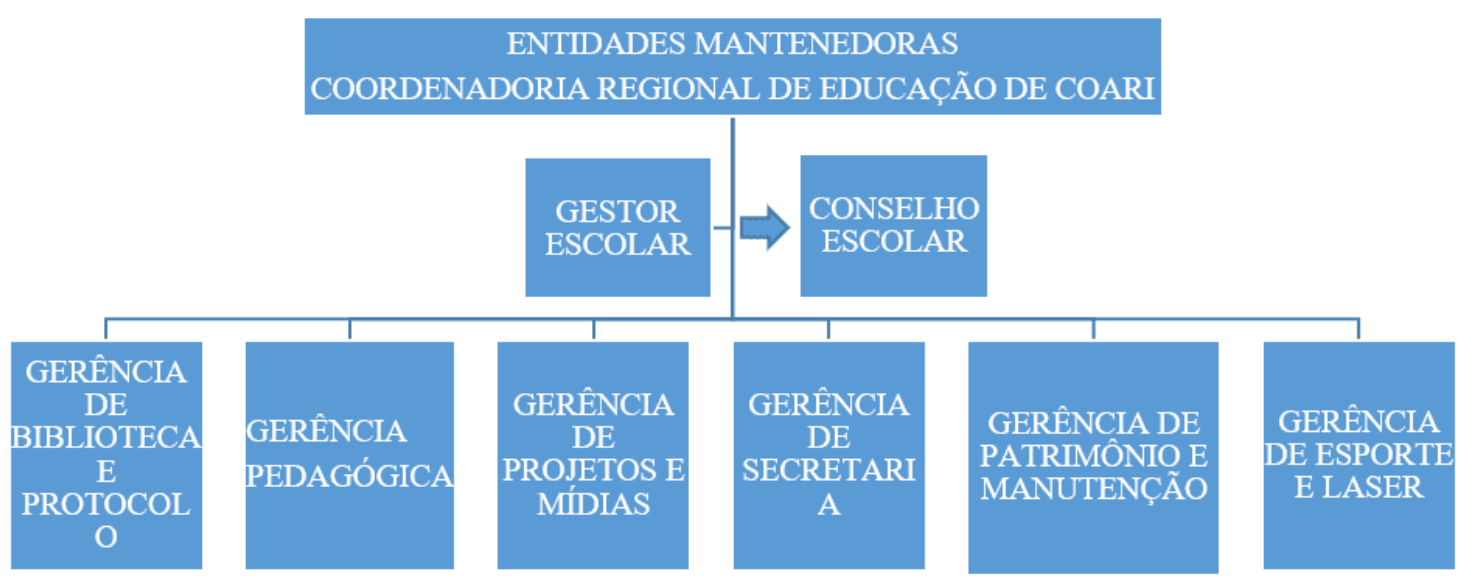

Fonte: XAVIER, 2016.

Criou-se nova estrutura organizacional de gestão escolar, com autorização da Coordenaria Regional de Educação de Coari que, por sua vez, cumpri as diretrizes da Secretaria Estadual de Educação e qualidade de Ensino do Amazonas-SEDUC-AM, cujas denominações e atribuições são:

Entidades Mantenedoras - fornecer a Gestão suporte necessário à manutenção e ao funcionamento da escola.

Gestão Escolar - responsável pela administração da escola, manutenção de contato direto com educadores e alunos, determinação de metas e objetivos, controle e avaliação dos resultados da escola. 
Conselho Escolar - órgão colegiado composto por representantes de todos os segmentos da comunidade escolar, participa da gestão administrativa, pedagógica e financeira da escola.

Gerência de Biblioteca e Protocolo - disponibiliza, controla e recebe os livros dos alunos, como também incentiva a prática de leitura e protocola a entrada e saída de documentos na escola.

Gerência Pedagógica - acompanha o processo de aprendizagem dos alunos, avaliando os rendimentos, como também auxilia o professor na elaboração de planejamentos, objetivando melhores resultados.

Gerência de Projetos e Mídias - incentiva a criação e implantação de novos projetos, como ainda introduz e controla novas mídias educacionais na escola.

Gerência de Secretaria - mantém atualizados registros, arquivos de documentação dos alunos e dos funcionários, além de comunicados e expedições para apoiar o desenvolvimento do processo escolar.

Gerência de Patrimônio e Manutenção - cuida do patrimônio, mantém atualizado o inventário dos bens materiais, como também procede às manutenções preventivas na estrutura física da escola.

Gerência de Esporte e Laser - responsável pelo incentivo das práticas esportivas em todas as modalidades, orienta e acompanha os alunos nos jogos escolares, auxilia os professores de Educação Física na elaboração e aplicação de aulas.

Os projetos existentes na escola, para serem implementados no transcorrer do ano letivo, tiveram que ser executados diferentemente dos desenvolvidos em anos anteriores, isto é, de forma mais planejada e sob a coordenação direta do gestor da escola, envolvendo a comunidade escolar, de acordo como descrito no Quadro 1. 
Quadro 1 - Descrição dos projetos implementados na Escola Estadual Nossa Senhora do Perpétuo Socorro, em 2015.

\begin{tabular}{|c|c|c|c|}
\hline $\begin{array}{l}\text { Projetos } \\
\text { desenvolvidos }\end{array}$ & Objetivos & Participantes & $\begin{array}{l}\text { Atividades } \\
\text { desenvolvidas }\end{array}$ \\
\hline $\begin{array}{l}\text { Dia da Família } \\
\text { na Escola }\end{array}$ & $\begin{array}{l}\text {-Incentivar a } \\
\text { participação da família } \\
\text { na escola. } \\
\text {-Proporcionar } \\
\text { momentos de interação } \\
\text { entre: gestão, } \\
\text { professores alunos e } \\
\text { pais. }\end{array}$ & $\begin{array}{l}\text { Comunidade } \\
\text { Escolar. }\end{array}$ & $\begin{array}{l}\text {-Organização do } \\
\text { Ginásio da Escola para } \\
\text { receber a família dos } \\
\text { alunos, com lanches, } \\
\text { palestras, } \\
\text { brincadeiras, sorteios } \\
\text { de brindes e solicitar } \\
\text { sugestões dos pais } \\
\text { para melhoria da } \\
\text { escola. }\end{array}$ \\
\hline $\begin{array}{l}\text { Gincana de } \\
\text { Matemática }\end{array}$ & $\begin{array}{l}\text {-Implementar atividades } \\
\text { lúdicas voltadas ao } \\
\text { desenvolvimento do } \\
\text { raciocínio lógico. }\end{array}$ & $\begin{array}{l}\text { Gestão } \\
\text { escolar, } \\
\text { gerência } \\
\text { pedagógica, } \\
\text { professores e } \\
\text { alunos. }\end{array}$ & $\begin{array}{llr}\text {-Utilização } & & \text { dos } \\
\text { conteúdos } & \text { das aulas } \\
\text { teóricas } & \text { para } & \text { as } \\
\text { disputas } & \text { entre } & \text { as } \\
\text { turmas. } & & \\
& & \end{array}$ \\
\hline $\begin{array}{l}\text { Mostra } \\
\text { Química }\end{array}$ & $\begin{array}{l}\text {-Oportunizar aos } \\
\text { estudantes da escola a } \\
\text { materialização dos } \\
\text { conceitos estudados em } \\
\text { sala de aula. Projeto de } \\
\text { incentivo ao estudo e à } \\
\text { pesquisa aplicada à } \\
\text { Química. }\end{array}$ & $\begin{array}{l}\text { Gestão } \\
\text { escolar, } \\
\text { gerência } \\
\text { pedagógica, } \\
\text { professores } \\
\text { de Química e } \\
\text { alunos. }\end{array}$ & $\begin{array}{l}\text {-Elaboração de } \\
\text { experimentos no } \\
\text { laboratório da escola. } \\
\text {-Apresentação para } \\
\text { comunidade escolar. } \\
\text {-Premiação do melhor } \\
\text { experimento } \\
\text { desenvolvido. }\end{array}$ \\
\hline
\end{tabular}




\begin{tabular}{|c|c|c|c|}
\hline $\begin{array}{l}\text { Cor da } \\
\text { Cultura }\end{array}$ & $\begin{array}{l}\text {-Desenvolver na escola } \\
\text { Projeto educativo do } \\
\text { MEC e parceiros, por } \\
\text { meio das disciplinas de } \\
\text { Ciências Humanas. }\end{array}$ & $\begin{array}{l}\text { Gestão } \\
\text { escolar, } \\
\text { gerência } \\
\text { pedagógica, } \\
\text { professores e } \\
\text { alunos. }\end{array}$ & $\begin{array}{l}\text {-Organização de feira } \\
\text { cultural. } \\
\text {-Apresentação de } \\
\text { projetos culturais que } \\
\text { valorizem a cultura } \\
\text { negra e local. } \\
\text {-Exposição de } \\
\text { produtos regionais. }\end{array}$ \\
\hline
\end{tabular}

Fonte: próprio autor.

Com a implementação dos projetos existentes na escola, observou-se maior motivação de professores, alunos e comunidade escolar, o que possibilitou a execução de novos projetos no campo das modalidades de ensino-aprendizagem, conforme Quadro 2.

Quadro 2 - Descrição dos projetos implantados na Escola Estadual Nossa Senhora do Perpétuo Socorro, em 2015.

\begin{tabular}{|c|c|c|c|}
\hline Projetos & Objetivos & Participantes & Metodologias \\
\hline $\begin{array}{l}\text { SOE - } \\
\text { Serviço de } \\
\text { Orientação } \\
\text { ao } \\
\text { Estudante }\end{array}$ & $\begin{array}{l}\text {-Contribuir com o } \\
\text { desenvolvimento de uma } \\
\text { cultura de comunidade } \\
\text { escolar e facilitar a } \\
\text { adaptação do aluno a esse } \\
\text { ambiente, buscando } \\
\text { integração entre aluno- } \\
\text { aluno, aluno-professor, } \\
\text { aluno-colaborador, aluno- } \\
\text { direção e aluno sociedade. }\end{array}$ & $\begin{array}{l}\text { Comunidade, } \\
\text { escolar, gestão } \\
\text { escolar e } \\
\text { gerência } \\
\text { pedagógica. }\end{array}$ & $\begin{array}{l}\text {-Palestras com } \\
\text { profissionais } \\
\text { qualificados para } \\
\text { alunos da escola; } \\
\text {-Orientação, logo } \\
\text { após a prática de } \\
\text { alguma infração por } \\
\text { parte dos alunos. }\end{array}$ \\
\hline
\end{tabular}




\begin{tabular}{|c|c|c|c|}
\hline $\begin{array}{l}\text { Conselho } \\
\text { Disciplinar } \\
\text { da Escola }\end{array}$ & $\begin{array}{l}\text {-Detectar os casos de } \\
\text { indisciplina; } \\
\text {-Aplicar advertências e } \\
\text { medidas disciplinares aos } \\
\text { alunos que confrontarem } \\
\text { os dispositivos do } \\
\text { Regimento Interno da } \\
\text { Escola. }\end{array}$ & $\begin{array}{l}\text { Professores, } \\
\text { gerência } \\
\text { pedagógica e } \\
\text { gestão escolar. }\end{array}$ & $\begin{array}{l}\text {-Registrar ocorrência } \\
\text { indisciplinar; } \\
\text {-Comunicar aos } \\
\text { pais; } \\
\text {-Aplicar punições, de } \\
\text { acordo com o } \\
\text { estabelecido nas } \\
\text { normas internas da } \\
\text { escola. }\end{array}$ \\
\hline $\begin{array}{l}\text { Feira do } \\
\text { Livro } \\
\text { Didático }\end{array}$ & $\begin{array}{l}\text {-Distribuição gratuita de } \\
\text { livros didáticos não mais } \\
\text { utilizados na rede de } \\
\text { ensino do estado do } \\
\text { Amazonas; } \\
\text {-Incentivar a leitura em } \\
\text { todas as suas } \\
\text { possibilidades. }\end{array}$ & $\begin{array}{l}\text { Gestão escolar, } \\
\text { gerência de } \\
\text { biblioteca, } \\
\text { professores, } \\
\text { gerência } \\
\text { pedagógica e } \\
\text { alunos. }\end{array}$ & $\begin{array}{l}\text {-Exposição dos } \\
\text { livros no auditório, às } \\
\text { sextas-feiras, para } \\
\text { alunos de outras } \\
\text { escolas, } \\
\text { universidades, pais e } \\
\text { comunidade escolar, } \\
\text { com distribuição } \\
\text { gratuita. }\end{array}$ \\
\hline
\end{tabular}

Fonte: próprio autor.

\section{RESULTADOS ALCANÇADOS}

No decorrer do processo de captação da realidade, percebeu-se que, com as adequações na estrutura física da escola, o estabelecimento de nova estrutura organizacional, a introdução e implementação de novos projetos, foi possível criar ambiente favorável para a prática das metodologias ativas e, consequentemente, proporcionar melhorias significativas para o ensino e a aprendizagem dos educandos.

O projeto Dia da Família na Escola proporcionou momentos de interação entre alunos e familiares, estabeleceu vínculo família/ escola, como também mostrou aos pais a 
importância da participação destes nas tomadas de decisão da escola. A Gincana de Matemática estimulou o trabalho em grupo para resolução de desafios matemáticos e do cotidiano dos discentes. A Mostra de Química contribuiu para estabelecer uma ponte real entre o que é ensinado na escola e o vivenciado nas rotinas diárias. O Projeto Cor da Cultura estimulou a valorização da cultura local e o reconhecimento da contribuição da cultura negra à sociedade brasileira. O Projeto SOE disseminou entre a comunidade escolar as orientações do Regimento Interno da Escola. O Conselho Disciplinar proporcionou aos alunos maior conscientização de direitos e deveres, diminuindo, consideravelmente, a indisciplina na escola. A Feira do Livro Didático contribuiu com a comunidade e as instituições de ensino, por meio da doação do livro didático, tornando-o instrumento de incentivo à leitura.

Após os resultados obtidos com a implementação dos projetos existentes na escola, observou-se maior motivação por parte de professores, alunos e comunidade escolar, possibilitando, assim, a execução de novos projetos que vieram acrescentar novas estratégias no campo das modalidades de ensino-aprendizagem, proporcionando aos alunos o desenvolvimento de uma cultura de comunidade escolar, a maior conscientização de direitos e deveres, além de incentivo à prática da leitura em todas as possibilidades.

Quanto ao resultado nos índices de aprendizagem, de acordo com o Sistema Integrado de gestão Educacional do Amazonas (SIGEAM), em 2014, a escola apresentou índice de aprovação dos alunos de 77,40\%, abaixo da média das outras escolas do município que foi $82,06 \%$. Em 2015, após intervenções, a escola atingiu índice de $92,84 \%$, superando a média das outras que foi de $79,91 \%$.

\section{CONSIDERAÇÕES FINAIS}

Pensar em ensino médio inovador e metodologias ativas é, sobretudo, entender que a aprendizagem deve ser significativa e, por sua vez, apresentar diversas possibilidades e estratégias de aplicação. 
A experiência vivenciada, por gestores, pedagogos, professores e corpo social da escola, proporcionou o repensar de práticas com base nas metodologias ativas que, por sua vez, buscou ajudar o aluno a explorar o próprio potencial, por meio de diferentes abordagens de aprendizagem, como resolução de problemas, discussão em grupo, atividades de reflexão e ações que promoveu conhecimento analítico sobre os conteúdos desenvolvidos.

A prática relatada mostrou que a valorização do conhecimento a partir de atividades em grupo é um dos caminhos para o aprimoramento do pensamento crítico, fazendo com que os estudantes se sintam estimulados a avaliar, criar e analisar as mais diversas temáticas abordadas no processo de ensino-aprendizagem.

Constatou-se que durante o processo de implementação do PROEMI, mediado pelas metodologias ativas, os discentes aperfeiçoaram não as habilidades mencionadas, além das competências socioeconômicas, de motivação, autoestima, comunicação e autocontrole, que foram consideradas essenciais para formação do educando.

Os projetos implementados de forma mais específica possibilitaram a reflexão de discentes e docentes, bem como da comunidade escolar, Coordenaria Regional de Educação de Coari, além de proporcionar ao gestor da escola a realização de novos projetos.

Os desafios enfrentados para implementação das práticas inovadoras serviram para fomentar a cultura de grupo e proporcionar trabalho interdisciplinar, envolvendo a comunidade escolar, que possibilitou aos alunos da escola superarem os índices de aprendizagem referente ao ano anterior.

\section{REFERÊNCIAS}

ANDRADE, L. R. S. Os desafios da SEDUC/AM no monitoramento do Programa Ensino Médio Inovador nas escolas estaduais. 2015. 147f. Dissertação (Mestrado Profissional em Gestão e Avaliação da Educação Pública) - Programa de Mestrado Profissional em Gestão e Avaliação da Educação Pública, Centro de Políticas Públicas 
e Avaliação da Educação, Faculdade de Educação, Universidade Federal de Juiz de Fora, Juiz de Fora, MG, 2015.

BERGMANN, J.; SAMS, A. Sala de aula invertida: uma metodologia ativa de aprendizagem. Rio de Janeiro: LTC, 2016.

BRASIL. Lei no 9.394, de 20 de dezembro de 1996. Estabelece as diretrizes e bases da educação nacional. Diário Oficial da União, Brasília, DF, 23 dez. 1996, p. 27.833.

BRASIL. Ministério da Educação. Portaria no 971, de 9 de outubro de 2009. Institui o Programa Ensino Médio Inovador e dá outras providências. Brasília: Ministério da Educação, 2009.

MOTA, A. R.; ROSA, C. T. W. Ensaio sobre metodologias ativas: reflexões e propostas. Revista Espaço Pedagógico, v.25, n.2, p.261-276, 2018.

RODRIGUES, L. et al. Metodologias ativas: sala de aula invertida-um novo jeito de aprender. Revista Mundi Engenharia, Tecnologia e Gestão, v. 4, n. 1, p.133-141, 2019.

SECReTARIA DE EDUCAÇÃO DO AMAZONAS (SEDUC-AM). Projeto Político Pedagógico Institucional da Escola Estadual Nossa Senhora do Perpétuo Socorro. $2^{\underline{a}}$ versão. Coari-AM: SEDUC-AM, 2016.

SILVA, I. C. E. O Papel da Coordenadoria Regional de Educação de Coari/AM na Implantação de Políticas Educacionais para o Ensino Médio. 2017. $174 f$. Dissertação (Mestrado Profissional em Gestão e Avaliação da Educação Pública) Programa de Mestrado Profissional em Gestão e Avaliação da Educação Pública, Centro de Políticas Públicas e Avaliação da Educação, Faculdade de Educação, Universidade Federal de Juiz de Fora, Juiz de Fora, MG, 2017.

VITELLI, R. F. Políticas públicas estaduais e os indicadores de qualidade do ensino médio: correlações e consequências. 2017. 204f. Tese (Doutorado em Educação) - 
Programa de Pós-Graduação em Educação da Universidade do Vale do Rio dos Sinos, UNISINOS, 2017.

Enviado: Setembro, 2020.

Aprovado: Outubro, 2020. 